\begin{tabular}{l} 
RACIC 6 (2) (2021) \\
UNIVERSITAS \\
\hline ABDURRAB \\
http://jurnal.univrab.ac.id/index.php/racic
\end{tabular}

\title{
KOMPETISI MODA ANGKUTAN UMUM DARAT (KORIDOR KOTA PADANG PANJANG - PADANG, SUMATERA BARAT)
}

\author{
Angelalia Roza ${ }^{1}$, Andi Mulya Rusli ${ }^{2}$, Muhammad Amrullah Saputra $^{3}$ \\ ${ }^{1,3}$ Program Studi Teknik Sipil, Fakultas Teknik, Institut Teknologi Padang \\ Jl. Kandis Raya No.6, Kota Padang, Sumatera Barat 25173 \\ *e-mail : angelaliaroza@gmail.com \\ *Telp : 085364392830 \\ Kementrian Pekerjaan Umum dan Perumahan Rakyat, Indonesia
}

\begin{abstract}
InfoArtikel Abstrak
Kota Padang merupakan kota pusat ekonomi dan pendidikan di Sumatera Barat. Hal ini menjadikan munculnya pergerakan yang berasal dari kota Padang Panjang menuju

Sejarah Artikel:

Kota Padang. Adapun tujuan dari penelitian ini adalah untuk Mengidentifikasi faktor yang mempengaruhi pelaku perjalanan dalam memilih moda di kawasan kajian.

Diterima : Maret 2021 Diamati terjadi kompetisi moda transportasi umum darat antara Minibus dengan Disetujui : Desember 2021 Dipublikasikan : Des 2021 Mobil Travel dari Padang Panjang menuju padang. Menurut persepsi responden, alasan dalam pemilihan moda adalah karena biaya, frekuensi keberangkatan, kenyamanan, waktu perjalanan, keamanan dan fasilitas. Pemodelan pemilihan moda dilakukan menggunakan persamaan regresi linear berganda dan Binomial Logit. Faktor-faktor yang mempengaruhi pemilihan moda (y) secara signifikan yaitu

Keywords: variabel biaya $\left(X_{1}\right)$, variabel waktu perjalanan $\left(X_{2}\right)$, dan variabel kenyamanan $\left(X_{3}\right)$, dengan nilai $\mathrm{R}^{2}=0,516$.
\end{abstract}

Regresi Linier Berganda, Alasan Pemilihan Moda, Kompetisi Moda

Kata Kunci: Regresi Linier Berganda, Alasan Pemilihan Moda, Kompetisi Moda

\section{Abstract}

The Padang city is the center of economy and education in West Sumatra. This makes the emergence of movements originating from the city of Padang Panjang to the city of Padang. The purpose of this study is to identify the factors that influence travelers in choosing modes in the study area. It was observed that there was a competition for public land transportation modes between Minibus and Travel Car from Padang Panjang to Padang. According to respondents' perceptions, the reason for choosing the mode was due to cost, time departure, comfort, safety and facilities. Mode selection modeling is carried out using multiple linear regression equations and binomial logit using SPSS tools. The factors that influence the choice of mode (y) significantly are the cost variable $\left(\mathrm{X}_{1}\right)$, travel time variable $\left(\mathrm{X}_{2}\right)$, and comfort variable $\left(X_{3}\right)$, with $R^{2}=0,516$.

Kata Kunci: Multiple Linear Regression, Mode Choice reason, mode competition 
Alamat korespondensi:

ISSN 2527-7073

Kandis Raya No.6, Kota Padang, Sumatera Barat 25173

E-mail: angelaliaroza@gmail.com

\section{PENDAHULUAN}

Kota Padang merupakan kota yang menjadi pusat pergerakan ekonomi dan pendidikan di Sumatera Barat. Luas wilayah kota Padang adalah $694,96 \mathrm{~km}^{2}$ dengan jumlah penduduk 939.112 jiwa dan kepadatan penduduk sekitar 1351,31 jiwa/ $\mathrm{km}^{2}$. Kota Padang terdiri dari 19 Kabupaten dan Kota yang terbagi atas lima kecamatan, yaitu Bungus Teluk Kabung, Koto Tangah, Kuranji, Lubuk Begalung, Lubuk Kilangan, Nanggalo, Padang Barat, Padang Selatan, Padang Timur, Padang Utara, dan Pauh. Jarak Pusat Kota Padang Panjang dengan kota Padang Jarak adalah sekitar 77,6 km. Sarana transportasi yang digunakan untuk mengakomodasi pergerakan dari dari Kota Padang Panjang menuju kota Padang saat ini diantaranya menggunakan kendaraan umum seperti Minibus, Travel dan kendaraan pribadi baik mobil ataupun sepeda motor (Gambar 1) . Banyak pertimbangan pelaku perjalanan dalam memilih moda angkutan pribadi ataupun angkutan umum. Alasan umum yang mudah dideteksi adalah alasan biaya dan waktu. Namun sebenarnya dalam pengambilan keputusan pemilihan moda, ada banyak variabel yang menjadi pertimbangan. Maka, penelitian ini dilakukan untuk (1) Mengidentifikasi faktor yang mempengaruhi pemilihan moda transportasi umum darat (minibus dan travel) pada koridor Padang Panjang menuju Padang dan (2) mendapatkan model pemilihan moda dengan mempertimbangkan variabel biaya $\left(X_{1}\right)$, variabel waktu perjalanan $\left(X_{2}\right)$, dan variabel kenyamanan $\left(\mathrm{X}_{3}\right)$.

\section{TINJAUAN PUSTAKA}

Karakteristik perjalanan terkait pelaku perjalanan dapat ditinjau dari beberapa variabel seperti jenis kelamin, umur, pekerjaan, jumlah pendapatan. Sedangkan Karakteristik perjalanan yang terkait moda diantaranya meliputi variabel biaya, frekuensi keberangkatan, kenyamanan, waktu perjalanan, keamanan dan fasilitas.

\section{METODE PENELITIAN}

\section{Pengumpulan Data}

Tahapan pengumpulan data melalui survei lapangan dan studi literatur. Data yang dikumpulkan dalam keperluan analisis di koridor Pang Panjang menuju Padang (Gambar 1) ini meliputi data primer dan data sekunder.

- Data primer diperoleh secara langsung dari lokasi penelitian melalui wawancara dan observasi atau pengamatan langsung terhadap objek penelitian. Data primer diperoleh dengan cara membagikan kuisoner kepada responden yang melakukan perjalanan ke Kota Padang. Penyebaran kuisioner ini dilakukan pada hari kerja dan hari libur. Penyebaran kueisioner ini melibatkan 4 orang. Lokasi titik penyebaran kuisioner adalah Terminal Bukit Sarungan, Padang Panjang.

- Data sekunder diperoleh melalui studi literatur yang berhubungan dengan lingkup penelitian. Data sekunder yang kumpulkan meliputi peta lokasi survey, Jumlah penduduk, jarak, dll. 


\section{Penentuan Jumlah Sampel}

Dikutip dari field, A. (2009) dalam Roza (2015) bahwa untuk menguji overal fit pada model regresi linier, ukuran sampel minimum yang dibutuhkan sama dengan 50+8k (diman $\mathrm{k}$ adalah jumlah prediktor). Bila mempertimbangkan jumlah populasi yang terdapat pada suatu kawasan dapat digunakan rumus Slovin (Wicaksono, 2010). Analisis regresi linier dilakukan terhadap 200 sampel responden.
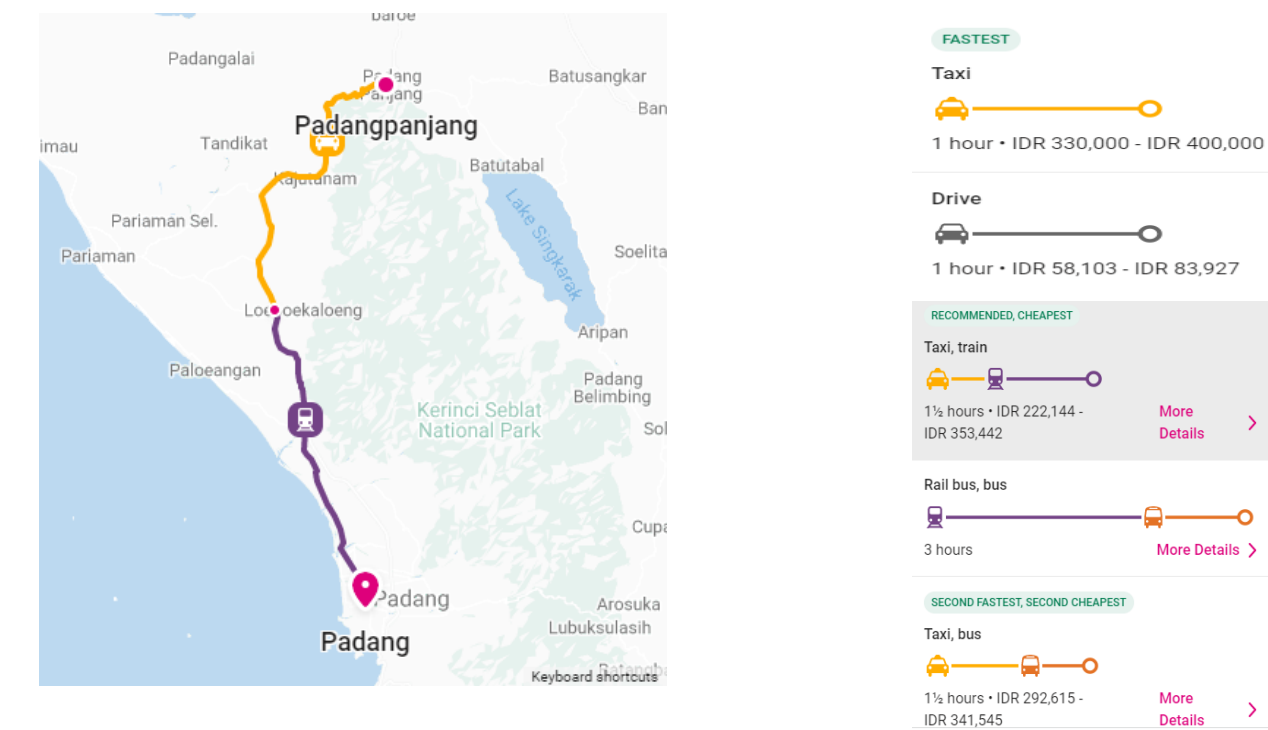

Gambar 1. Koridor Padang Panjang menuju Padang ( www.rome2rio.com. 2021)

\section{Tahap Analisis Data}

Tahap analisis data dilakukan menggunakan teknik analsis statistik deskriptif dan inferensial. Teknik analisis deskriptif digunakan dalam penyajian data karakteristik perjalanan. Sementara dalam analisa kompetisi moda digunakan teknik analisis inferensial. Digunakan pula Teknik mode choice untuk mengolah data Stated preference yang dikumpulkan Yang L., et. all., 2009). Untuk menghitung probabilitas preferensi bus dan mengevaluasi persepsi pengguna bus, digunakan transformasi linear logit biner model (Masmuda. M. 2011; Roza, 2013). Pengolahan data dilakukan dengan menggunakan software excel dan SPSS. Terlebih dahulu dilakukan uji validitas dan uji reliabilitas untuk memastikan data dapat digunakan, valid dan reliable. Uji Realibilitas dilakukan menggunakan menggunakan cronbach alpha.

Analisis regresi linier berganda dipakai untuk menghitung besarnya pengaruh secara kuantitatif dari suatu perubahan kejadian (variabel X) terhadap kejadian (variabel Y) dan telah banyak digunakan pada beberapa penelitian (Roza, A., dkk 2013a, 2015; 2019). Correlation matrix analysis terlebih dahulu telah dilakukan sebelum melakukan analisa regresi ( Astria $\mathrm{H}$., 2016; Roza, A., dkk., 2020). Hal ini bertujuan memastikan bahwa tidak terjadi Kolinearitas dan tidak ada variabel yang tertinggal pada model regresi. Uji asumsi klasik harus terpenuhi meliputi uji normalitas, uji multikolinearitas, heteroscedastisitas dan uji autokorelasi. Kontribusi variabel antara terhadap variabel terikatnya dapat dilihat melalui koefisien korelasi (R). Jika koefisien Korelasi yang diperoleh mendekati 1 (satu) maka dapat dikatakan semakin kuat model tersebut. 


\section{HASIL DAN PEMBAHASAN}

\section{A. Data Karakteristik Responden}

Karakteristik responden pelaku perjalanan pada kawasan kajian adalah sebagai berikut. Sebesar 58,8\% dari responden adalah laki-laki, dan sisanya (41.5\%) perempuan. Sebagian besar responden yang melakukan perjalanan ke kota Padang berumur $<15-25$ th yaitu sebesar $55.5 \%$, dan $16 . \%$ berumur antara $26-35$ th. Pendidikan responden adalah pelajar sekolah menengah $(65,5 \%)$ sedangkan $19 \%$ berpendidikan diploma / sarjana. Pelaku perjalanan yang menggunakan moda transportasi umum darat ini didominasi pelajar/ mahasiswa (45\%), dan Pegawai swasta / wiraswasta 33,5\%. Pendapatan sebagian responden kurang dari 1.000 .000 perbulannya $(50 \%)$, dan sisa nya berada pada rentang pendapatan $1-2$ juta $(16,5 \%)$ dan 2-3 juta ( 10.5\%) 3- 4 juta (17\%). Dilihat dari frekuensi perjalanan responden, sebagian besar responden (53\%) melakukan perjalanan 1-2x seminggu, dan 29\% melakukan perjalanan 1-2x sebulan.

\section{B. Data Karakteristik Moda Transportasi}

Karakteristik perkjalanan dapat dikaitkan dengan karakteristik moda. Moda yang digunakan responden untuk melakukan perjalanan di Koridor Padang Panjang menuju Padang diantaranya Hanya Mini Bus (31\%) dan Hanya Mobil Travel (20\%) sedangkan 49\% responden penah menggunakan kedua moda tersebut. Apabila kedua moda tersebut dibandingkan, ternyata minibus lebih digemari $(64,5 \%)$ dari pada mobil travel $(35,5 \%)$. Variabel yang menjadi pertimbangan responden dalam pemilihan moda diantaranya (Gambar 2) variabel biaya $(39,0 \%)$, variabel kenyamanan $(23,5 \%)$, variabel waktu perjalanan $(17,5 \%)$, variabe keamanan $(12,5 \%)$, variabel fasilitas $(5,0)$ dan variabel Lainnya $(2,5 \%)$.

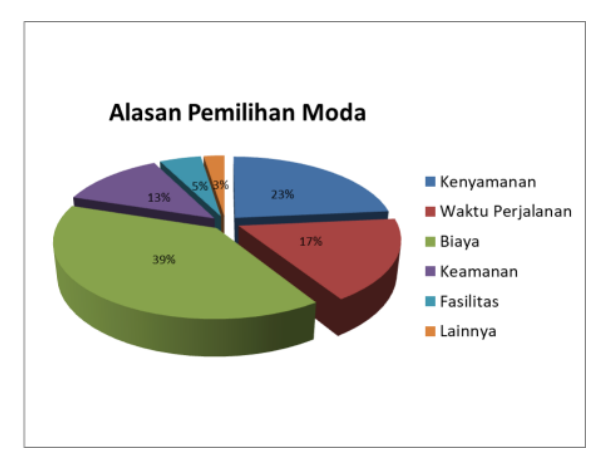

Gambar 2. Pertimbangan Responden dalam pemilihan moda

\section{Analisa Regresi Linier Berganda}

Pemodelan pemilihan moda teknik analisis regresi linier berganda menggunakan binomial logit model. Variabel yang dipertimbangkan dalam pemodelan yang akan diregresikan yaitu variabel biaya $\left(\mathrm{X}_{1}\right)$, variabel waktu perjalanan $\left(\mathrm{X}_{2}\right)$, dan variabel kenyamanan $\left(\mathrm{X}_{3}\right)$. Penentuan model regresi terbaik dilakukan dengan bantuan tools SPSS melalui dua metode yaitu metode Enter dan metode Stepwise. 
Roza, A., Rusli, A. M., Saputra, M.A. / Jurnal Rab Contruction Research 6 (2) (2021)

Tabel 1. Pemodelan menggunakan Metode Enter dan Stepwise

\begin{tabular}{|c|c|c|c|c|c|c|c|}
\hline & \multirow[t]{2}{*}{ Model } & \multicolumn{2}{|c|}{$\begin{array}{c}\text { Unstandardized } \\
\text { Coefficients }\end{array}$} & \multirow{2}{*}{$\begin{array}{c}\text { Standardized } \\
\text { Coefficients } \\
\text { Beta }\end{array}$} & \multirow[t]{2}{*}{$\mathrm{t}$} & \multirow[t]{2}{*}{ Sig } & $\begin{array}{c}\text { Collinearity } \\
\text { Statistics }\end{array}$ \\
\hline & & B & $\begin{array}{l}\text { Std. } \\
\text { Error }\end{array}$ & & & & Tolerance VIF \\
\hline \multirow[t]{2}{*}{1} & (Constant) & 2.771 & .124 & & 22.305 & .000 & \\
\hline & $\mathrm{X}_{2}$ & -.105 & .004 & -.422 & -23.753 & .000 & 1.0001 .000 \\
\hline \multirow[t]{3}{*}{2} & (Constant) & 4.131 & .107 & & 38.533 & .000 & \\
\hline & $\mathrm{X}_{2}$ & -.153 & .004 & -.615 & -40.105 & .000 & .8841 .131 \\
\hline & $\mathrm{X}_{1}$ & $-3.351 \mathrm{E}-5$ & .000 & -.565 & -36.871 & .000 & .8841 .131 \\
\hline \multirow[t]{4}{*}{3} & (Constant) & .548 & .227 & & 2.412 & .016 & \\
\hline & $X_{1}$ & $-3.565 \mathrm{E}-5$ & .000 & -.601 & -41.094 & .000 & .8671 .153 \\
\hline & $\mathrm{X}_{2}$ & -.162 & .004 & -.648 & -44.384 & .000 & .8691 .151 \\
\hline & $X_{3}$ & .540 & .031 & .244 & 17.640 & .000 & .9731 .028 \\
\hline
\end{tabular}

Dimana :

$\mathrm{Y}=$ Kompetensi Moda $; \mathrm{X}_{1}=$ Biaya Perjalanan; $\mathrm{X}_{2}=$ Waktu Perjalanan $\mathrm{X}_{3}=$ Kenyamanan

Variabel yang dinilai signifikan mempengaruhi model akan diuji secara parsial dan secara simultan. Dilakukan uji - t parsial, uji F / ANOVA, uji determinasi R2, uji multikolinearitas dan uji autokorelasi terhadap masing- masing model. Terlihat dari hasil simulasi tersebut bahwa variabel bebas $(\mathrm{X})$ berpengaruh signifikan terhadap variabael terikat $(\mathrm{Y})$ dan tidak terlihat adanya masalah terkait multikolinearitas dan autokorelasi.

\section{Pengujian Model (Uji Statistik)}

\section{Uji signifikasi (Uji - t ) partial}

Dasar pengambilan keputusan dalam uji $-\mathrm{t}$ :

$\mathrm{H} 0$ diterima dan $\mathrm{H} 1$ ditolak jika nilai $\mathrm{t}$ hitung $<\mathrm{t}$ tabel atau jika nilai Sig. $>0,05$

$\mathrm{H} 0$ ditolak dan $\mathrm{H} 1$ diterima jika nilai $\mathrm{t}$ hitung $>\mathrm{t}$ tabel atau jika nilai Sig. $<0,05$

Dimana $\mathrm{t}$ tabel $=\mathrm{t}(\alpha / 2 ; \mathrm{n}-\mathrm{k}-1$ atau $\mathrm{df}$ residual), dengan $\alpha=5 \%, \mathrm{n}=$ jumlah sampel dan $\mathrm{k}=$ jumlah variabel $\mathrm{x}$.

Tabel 2. Uji - $t$ variabel independent

\begin{tabular}{|c|c|c|c|c|c|c|c|}
\hline \multirow{2}{*}{ Model } & \multicolumn{2}{|c|}{$\begin{array}{l}\text { Unstandardized } \\
\text { Coefficients }\end{array}$} & \multirow{2}{*}{$\begin{array}{c}\text { Standardized } \\
\text { Coefficients }\end{array}$} & \multirow{2}{*}{$\mathrm{t}$} & \multirow{2}{*}{ Sig. } & \multicolumn{2}{|c|}{ Collinearity Statistics } \\
\hline & $\mathrm{B}$ & Std. Error & & & & Tolerance & VIF \\
\hline Intercept & .548 & .227 & & 2.412 & .016 & & \\
\hline $\mathrm{X}_{1}$ & $-3.565 \mathrm{E}-5$ & .000 & -.601 & -41.094 & .000 & .867 & 1.153 \\
\hline$X_{2}$ & -.162 & .004 & -.648 & -44.384 & .000 & .869 & 1.151 \\
\hline$X_{3}$ & .540 & .031 & .244 & 17.640 & .000 & .973 & 1.028 \\
\hline
\end{tabular}


Dapat dilihat dari Tabel 2, bahwa keseluruhan variabel $X_{1}, X_{2}$ dan $X_{3}$ terbukti signifikan. Dengan demikian dapat dikatakan bahwa variabel biaya $\left(\mathrm{X}_{1}\right)$, variabel waktu perjalanan $\left(\mathrm{X}_{2}\right)$, dan variabel kenyamanan $\left(\mathrm{X}_{3}\right)$ berpengaruh terhadap pemilihan moda transportasi $(\mathrm{Y})$.

\section{Uji - F / Anova}

Dasar pengambilan keputusan dalam Uji - F adalah sebagai berikut :

Jika nilai $\mathrm{F}$ hitung $>\mathrm{F}$ tabel dan nilai signifikansi $<0,05$, maka variabel independent secara simultan berpengaruh terhadap variabel dependent.

Jika nilai $\mathrm{F}$ hitung $<\mathrm{F}$ tabel dan nilai signifikansi $>0,05$, maka variabel independent secara simultan tidak berpengaruh terhadap variabel dependent.

Dimana $\mathrm{F}$ tabel $=\mathrm{F}(\mathrm{k} ; \mathrm{n}-\mathrm{k}$ atau df risidual $)$, dengan $\mathrm{n}=$ jumlah sampel dan $\mathrm{k}=$ jumlah variabel $\mathrm{x}$.

Tabel 3. Uji - F / Anova

\begin{tabular}{crrrrr}
\hline \multicolumn{7}{c}{ ANOVA $^{\text {a }}$} \\
\hline Model & Sum of Squares & df & Mean Square & F & \multicolumn{1}{c}{ Sig. } \\
\hline Regression & 1488.122 & 3 & 496.041 & 931.620 & $.000^{\mathrm{b}}$ \\
\hline Residual & 1382.239 & 2596 & .532 & & \\
\hline Total & 2870.362 & 2599 & & & \\
\hline
\end{tabular}

Dependent Variable: $\mathrm{Y}$

Predictors: (Constant), $\mathrm{X}_{3}, \mathrm{X}_{2}, \mathrm{X}_{1}$

\section{A. Uji Determinasi $\left(\mathbf{R}^{2}\right)$}

Hubungan antara variabel terikat dan variabel bebas dari masing-masing model dapat dilihat pad Tabel 4. Adapun beberapa kesimpulan yang bisa diambil yaitu:

Tabel 4. Uji Determinasi

\begin{tabular}{ccccc}
\hline R & R Square & Adjusted R Square & $\begin{array}{c}\text { Std. Error } \\
\text { of the Estimate }\end{array}$ & Durbin-Watson \\
\hline $.720^{\mathrm{a}}$ & .518 & .518 & .72969 & 1.511 \\
\hline
\end{tabular}

Dependent Variable: Y

Predictors: (Constant), $\mathrm{X}_{3}, \mathrm{X}_{2}, \mathrm{X}_{1}$

Maka, dari pemodelan yang dilakukan dapat disimpulkan bahwa model pemilihan moda yang terbaik yaitu :

$$
Y=3,089-2,596 X_{1}-0,015 X_{2}-0,010 X_{3}
$$

Dari model diamati hubungan antara variabel bebas dan variabel terikatnya mempunyai hubungan yang cukup kuat dengan nilai $\mathrm{R}^{2}=0,518$. Dapat dikatakan bahwa $55 \%$ variabel bebas $\mathrm{X}_{3}, \mathrm{X}_{2}, \mathrm{X}_{1}$ mempengaruhi pemilihan moda. Aketiga variabel tersebut adalah variabel biaya 
$\left(\mathrm{X}_{1}\right)$, variabel waktu perjalanan $\left(\mathrm{X}_{2}\right)$, dan variabel kenyamanan $\left(\mathrm{X}_{3}\right)$. Sedangkan $45 \%$ lainnya dipengaruhi oleh variabel lain yang tidak dipertimbangkan dalam model.

Apabila dihubungkan dengan faktor yang dipertimbangkan pelaku perjalanan dalam memilih moda antara mini bus dan travel pada koridor Padang Panjang menuju Padang (Gambar 2), maka ketiga variable berpengaruh yaitu biaya perjalanan, waktu perjalanan dan kenyamanan telah terbukti signifikan.

\section{KESIMPULAN}

Kompetisi moda angkutan umum darat di KoridorPadang Panjang menuju Padang dapat diamati dengan mengidentifikasi karakteristik perjalanan terkait pelaku perjalanan dan karakteristik moda. Karakteristik perjalanan terkait pelaku perjalanan dapat ditinjau dari beberapa variabel seperti jenis kelamin, umur, pekerjaan, jumlah pendapatan. Sedangkan Karakteristik perjalanan yang terkait moda diantaranya meliputi variabel biaya, frekuensi keberangkatan, kenyamanan, waktu perjalanan, keamanan dan fasilitas. Pemodelan pemilihan moda telah dilakukan menggunakan persamaan regresi linear berganda dan Binomial Logit. Faktor yang mempengaruhi pemilihan moda (y) telah dibuktikan secara signifikan yaitu variabel biaya $\left(\mathrm{X}_{1}\right)$, variabel waktu perjalanan $\left(\mathrm{X}_{2}\right)$, dan variabel kenyamanan $\left(\mathrm{X}_{3}\right)$, dengan nilai $\mathrm{R}^{2}=$ 0,516

\section{UCAPAN TERIMA KASIH}

Ucapan terima kasih kami sampaikan kepada pihak terkait di Institut Teknologi Padang yang telah membantu dan memberi saran untuk pelaksanaan dan penulisan hasil penelitian ini.

\section{DAFTAR PUSTAKA}

1. Astria, H., Kurnia, M., Ain A., E., 2016. Implementasi Metode Regresi Linier Sederhana Pada Penyajian Hasil Prediksi Pemakaian Air Bersih Pdam Way Rilau Kota Bandar Lampung Dengan Sistem Informasi Geofrafis. Jurnal Informatika Mulawarman. Vol. 11 No 2.

2. Yang, L., Choudhury, C. F., Ben-Akiva, M., 2009. Stated preference survey for new smart transport modes and services: Design, pilot study and new revision. Working Paper Series: Instituto Superior Tecnico, Universidade Tecnica de Lisbon, Portugal.

3. Field, A. 2009. Discovering statistic using SPSS. London: Sage.

4. Masmuda. M., 2011. Analisis Regresi Logistik Biner dan Aplikasinya untuk Mengidentifikasi faktor-faktor yang Mempengaruhi Tingkat Kesejahteraan Petani. Skripsi. Universitas Negeri Makassar. Makassar.

5. Roza, A., Koting, S., \& Karim, M. R. 2013a. Intercity land public transport challenges in developing country: A case study in Peninsular Malaysia.Paper presented at the Proceeding Journal of the Eastern Asia Society for Transportation Studies (EASTS), Taipe, Taiwan. 
6. Roza, Angelalia. Intercity land public transport modal choice by stated preference method: A case study in Kuala Lumpur-Penang corridor, unpublished Master Thesis, Faculty of Engineering, University Malaya. 2013.

7. Roza, A., Rusli, A. M., dan Karim. M. R., 2015. Tantangan Transportasi Umum Khususnya Moda Angkutan Darat Di Negara Berkembang : Studi Kasus Malaysia. Jurnal Teknik Sipil ITP. Vol. 2, No. 1, 2015.

8. Roza, A., Yusnita, Y., dan Mandasari. W., 2019. Permodelan Tarikan Perjalanan dengan Teknik Analisis Multiple Regression: Studi Kasus Kawasan Perbelanjaan Transmart, Kota Padang. Seminar Nasional SPI-4, 1-8. Padang, 10 Oktober 2019.

9. Roza, A., Yusnita, Y., Rusli, A. M., Muchlisin., 2020. Trip Attraction Model on the Education Center on Pangilun Mountain Area, Padang City.

10. Yusnita, Y., A. Roza, A. M. Rusli. 2020., Model Pemilihan Moda Berdasarkan Variabel Kepemilikan Kendaraan dan Katagori Luas Lahan Parkir dengan Teknik Analisis Regresi. Jurnal Pythagoras, Jurnal Program Studi Pendidikan Matematika. Vol. 9, No. 2,2020 . 